\title{
Federal Controlling and Auditing Activities of Safety Requirements for Tourism Facilities
}

\author{
${ }^{1}$ Cren Turner and Arjun Rampal \\ ${ }^{1}$ The Department of Sociology, University of North Carolina at Chapel Hill, NC, United States. \\ ${ }^{1}$ turner@unc.edu
}

\author{
Article Info \\ Journal of Journal of Enterprise and Business Intelligence (http://anapub.co.ke/journals/jebi/jebi.html) \\ Doi: https://doi.org/10.53759/5181/JEBI202101005 \\ Received 25 August 2020; Revised form 15 September 2020; Accepted 14 December 2020. \\ Available online 05 January 2021. \\ (C2021 Published by AnaPub Publications.
}

\begin{abstract}
The research aims to study the role of controlling and auditing bodies represented in the federal board of supreme audit in evaluating safety requirements for accidents in markets, malls, hotels, and tourism facilities, and the research included a case study represented in deciding policies and programs for the federal board of supreme audit, and indicate the strength or weakness of the control and auditing procedures in assessing safety requirements in tourism facilities, And its compatibility with the international requirements of the World Tourism Organization, However, the study recommended several proposals in order to create a design audit program in light of the requirements of the World Tourism Organization, and according to the World Tourism Organization report, which includes four dimensions which are the government dimension, Economic dimension, operational dimension, and the standard of tourism product quality.
\end{abstract}

Keywords - Auditing, Tourism, Accidents, Safety Requirements,

\section{INTRODUCTION}

Tourism is one of the great topics to study, and many kinds of literature has been written on this topic, however, tourism is often associated with fun, enjoyment, and entertainment, but some of us study within a historical or anthropological context, some people are interested in nature's sustainability and coexistence between humans, although humans sometimes they threaten this coexistence. Tourism has a long history, but it has rarely received major strategic attention as one of the meaningful industries that contribute to the development of the national economy. however, the basic requirements for tourism are the peace and security of travelers, which have not always been present throughout the history of mankind [1].

Tourism is one of the most important sectors that support the economy of many countries and an important source of financing public revenues in the public budget. Iraq is considered one of the most important countries in which tourism facilities vary, from its north, which is characterized by picturesque areas of mountains, valleys, springs, and waterfalls, to its south, which includes a number of marshes. This is classified under the World Heritage List, as it includes regions with geographical and environmental diversity, such as forests, desert areas, and agricultural areas, in addition to that, the presence of a large number of archaeological sites, mosques, religious shrines. It is worth mentioning that Iraq received in the seventies and eighties of the last century a large number of tourists annually, but wars and the blockade has led to a decline in demand for visiting the country, especially in term of religious tourism, and data from the Ministry of Culture, Tourism, and Antiquities indicate that the number of tourists who enter the country annually reaches five million tourists, At the present time, despite what Iraq owns of various tourist facilities, it does not contribute to supporting the state budget with a large amount of money, and government political programs are almost empty of items related to developing this important sector or educating people about its importance[2].

Despite the change in the political system, the government is still directly responsible for the various tourism facilities, including hotels, commercial markets, and other tourism facilities, despite the fact that many of them have been put up for investment. therefore, the federal board of supreme audit is responsible for evaluating the results of the activities of this tourist facility, however, in light of the successive economic problems facing the world in general, and Iraq in particular. and especially the spread of the Coronaviruses, which directly affected the global oil prices, and which led to a high deficit in the state's general budget, due to its dependence mainly on oil to finance revenues In general, the government should search for other sources to finance these revenues, and paying more attention to the country's tourism facilities, and given the fact that the federal board of supreme audit is auditing the work of its affiliated institutions, it is incumbent on controlling and auditing work, including evaluating safety requirements for accidents in all tourist facilities. 


\section{LITERATURE REVIEW}

The researchers relied on what has been dealt with from previous studies in the process of evaluating the report of the specialized body in the federal board of supreme audit in evaluating safety requirements for accidents in markets, shopping centers, hotels, and tourist facilities. A study [3] indicated the identification of the reports of the world conference of research and travel trade related to security and tourist risks held in Sweden in 1995, and the study emphasized the safety of tourism in a changing political and social environment, the complexity of tourism security and risk issues, however, the study reached the need for self-organization of the industry to achieve the goals of sustainable tourism development and a call to improve research on global tourism-related risks.

As for [4] study which aimed to identify the risks to the enterprising tourist in New Zealand and the important points that reduce these risks, as well as the development of guidelines for the improvement of effective safety management systems for adventure tourism, the study found that most of the client's injuries were in the sport of bungee jumping, snowboarding, and horse riding. As for the implementation of safety management instructions, adventurous tourism was applied inconsistently. A study [5] that aimed to assess customer opinions on the quality of tourism in Egypt, by measuring the extent of creativity of the tourism and innovative business environment as conditions necessary to satisfy them, however, the research results were obtained through two surveys, one of which is to measure the satisfaction of workers, and the second is by measuring the tourist satisfaction, The study reached a set of conclusions, the most important of which is that the tourism business environment in Egypt does not support the satisfaction of employees, due to the lack of an appropriate system to encourage employees to be creative and innovative; and in the field of tourist satisfaction, steps are still needed, including improving environmental conditions, and improving the quality of internal transport, And improving the level of safety and security conditions.

The study [6] aimed to identify the impact of crises on the inflows and outflows of tourist flows in Romania, and the extent of the impact of tourism security on the future development as a tourist destination for the country, and the study concluded that hotel managers should be aware of the need to ensure the security of tourists and that they be on Knowledge of procedures that reduce accidents or crises, and the availability of employees and technicians who have experience, skills, and knowledge in dealing with tourist safety and security.

As for the study [7], it indicates the conduct of safety tests on Thai tourist roads that are exposed to accidents of travel and tourism in a large way and the verification of problems in order to improve road safety, especially in dangerous areas, however, the study recommended to set out warning signs at both sides of the roads to remind drivers with extreme caution in order to reduce speed before turning. [8] the study aimed to identify the factors that affect the attraction of Indonesian medical tourists to Penang city in Malaysia, the number of participants in this study reached 25 participants from individuals who have experience in medical treatment in private hospitals or outpatient clinics in Penang Island, the study found that the effectiveness and accuracy of prescriptions and treatment on Penang Island attracted a large number of Indonesian medical tourists to Penang, Malaysia.

The study [9] aimed to contribute to achieving safety in tourist facilities in general, and in amusement parks for children in particular, and work to stop accidents that children are exposed to in amusement parks and games, due to their weak ability to prevent and survive, and the study recommended The need to strengthen confidence, as most of its visitors do not trust safety measures.

The study [11] aimed to identify the accidents that occurred in Chinese tourist hotels in 2016 and the extent of variation and the spatial and temporal difference in the occurrence of accidents in Chinese tourist residences and hotels. The researchers relied on their study on statistical analysis and found that there is a difference in accidents of Chinese residency and hotels in terms of time due to the changing crowding in the tourism season. As for the spatial aspect, the accidents of hotel tourists were primarily in the eastern coastal areas, then the central regions, and after the western regions, in descending order, and the most accidents occurred in places that do not apply the standards of tourist residency, and this helps in supervising safety in hotels, and taking effective measures Prevention against accidents in the tourism and hotel industry.

As for the study [12], it aimed to study the research activities of 160 research that published in English and Chinese journals, which relate to the security and safety of tourism for the period from 1990 to 2018, and the study concluded that English research is more comprehensive than Chinese English in this field, Because it takes into account both the demand and the supply sides of the tourism industry, however, Chinese journals study the importance and security of tourism in the tourism development process. The study [13] indicates the ability of European hotels to face natural disasters, and their ability to respond and adapt to these disasters, in order to sustain business in European hotels, and to achieve the goals of the study, the researchers relied on their study on the questionnaire form, and the research sample consisted of 63 European hotel managers, and the study found that hotels managed by managers with previous experience in the face of natural disasters or managers that have a long period of training in the hotel sector have great flexibility in dealing with natural disasters and allocate and provide the necessary funds for these purposes, however, the cooperation 
between the government and the private sector should be strengthened against natural disasters, in order to achieve sustainability from natural hazards.

As for the study [12], it aimed to identify the loyalty of tourists by studying the three factors represented by tourist attraction, tourism safety, and tourism facilities. however, the study concluded that the tourist attraction element has a positive impact on the loyalty of tourists through the satisfaction of tourists, as for the other factors represented by safety and tourism facilities have no effect on the loyalty of tourists.

The study [10] indicates the extent to which tourism events in Mooiplaas, South Africa, can be used to promote tourism and create job opportunities, and the study found that $82 \%$ of those surveyed agree that tourism events lead to the increase of the country's economic development, however, the strategic location of Mooiplaas, the cultural and heritage of the city, can be used to improve tourism. The study [11] reviews the assessment and measurement of the culture and safety of administrative and non-administrative employees in hotels, and the verification of the extent to which the working environments in the hotel industry emphasize the protection, safety, and culture of their employees, and the sample of the study was a number of employees working in five-star hotels, who number 229 employees. however, the researchers relied in their study on the questionnaire, and the study concluded that administrative and nonadministrative employees should work together to implement and obey the rules related to occupational health and safety and that the continuous evaluation of the psychological dimension of employees helps tourist companies to comfort Awareness of employees, their attitude towards safety and its importance in the workplace.

\section{The importance of auditing in tourism companies}

Auditing is one of the closely related functions of accounting jobs, as it aims to verify the accuracy of accounting information in order to express an impartial technical opinion on the validity and fairness of the financial statements of companies, in order to add confidence and credibility to the accounting information contained in those statements .

The believes that auditing contributes to improving the level of tourism activity and providing services, and reducing the level of information risks that users of financial statements need for tourism activities and that tourism company officials rely on the information provided by auditing results in making effective economic and administrative decisions.

however, ensuring the quality of the auditing is one of the main tasks in making effective administrative decisions in tourism companies, and given the importance of the auditing process in the field of tourism activities, therefore work should be done to increase the services provided on financial reporting standards and international standards related to tourism activities. because the internal audit provides reliable information to hotel tourism establishments and assists administration in determining the extent of deviations in actual data from what is planned and contributes to improving the performance of hotel tourism establishments. The quality of the auditing is one of the main tasks in making effective administrative decisions in tourism companies, and given the importance of the auditing process in the field of tourism activities, therefore, efforts should be made to increase the services provided by financial reporting standards and international standards related to tourism activities. A study [2] presented a safety organizational structure as shown in figure 1.

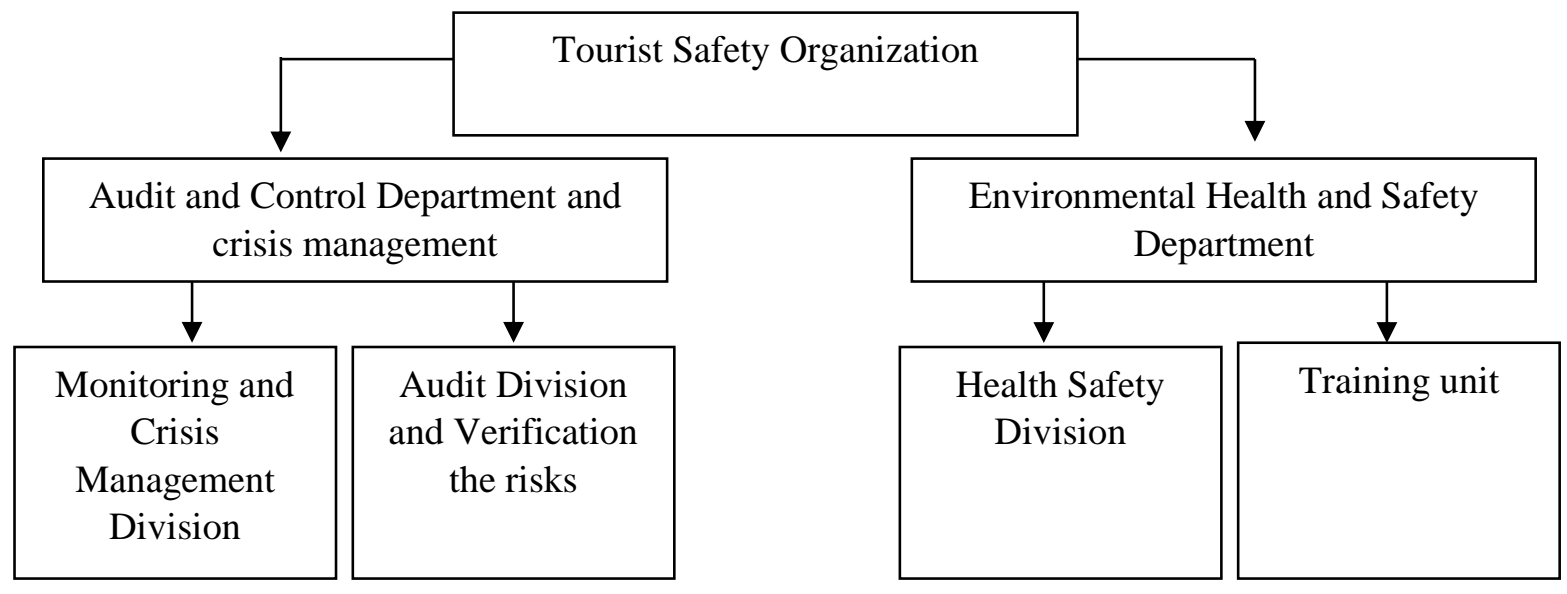

Fig 1. Safety Structure in Tourism Institutions

In [10] Safety in Tourist Facilities: An applied study on children amusement parks in the Kingdom of Saudi Arabia. 
It can be said that the auditing function is not limited to financial aspects only, but rather extends to assessing the risks that people may be exposed to in tourist facilities, in order to provide appropriate solutions with a view to reducing them. The controlling and auditing institutions function in this field lies within the function of performance auditing.

\section{Tourism and public budget revenue development}

Tourism is one of the dynamic economic sectors in which interest is increasing and the need for it in the world today, especially in those countries that consider this sector as one of the main tributaries in the development process due to the returns it generates for receiving countries because the presence of an integrated tourism industry includes several interacting elements such as planning, construction, good use of capabilities and running services, and choosing the appropriate location greatly contribute to attracting tourists continuously to provide hard currency incomes and the operation of simple and qualified employees, in addition to advancing the development not only in the tourism sector, but that includes other sectors in the economy. The tourism sector, as a service sector with distinction, has received a lot of attention from the United Nations Organization, in particular by one of its organizations specialized in the tourism sector, which is the "World Tourism Organization" 1975; with an increase in tourism contribution to achieving development in general and sustainable development in particular for many developing economies. The World Tourism Organization is an organization of an inter-governmental nature emanating from the International Federation of Official Tourism Authorities, based in Madrid, Spain, founded in 1975, and has become a United Nations agency specializing in international tourism.

However, scientific evidence and countries' experiences indicate a noticeable increase in the important role that tourism plays in general in development issues in its comprehensive concept in the economies of countries, as tourism institutions contribute significantly to attracting an important part of foreign exchange to implement comprehensive development plans through the types of foreign cash flows collected, whether from the contribution of foreign capital to investments in the tourism sector or tourism revenues obtained by the state, including the granting of entry visas and hotels revenue obtained by tourists, in addition to the daily spending of the tourist in return for tourist services that provided to them or through the sale of national products, goods, and folklore goods for tourists. believes that revenues from tourism institutions have become the first source of foreign exchange for about $38 \%$ of countries, and one of the five largest sources for the rest of the countries.

\section{RESEARCH METHODOLOGY}

The position of tourism in Iraq is no less important than many countries whose economy is heavily dependent on the tourism sector, and tourism can contribute averting the threat of rentier economy away from the nature of the economy, as oil in Iraq is the first source of imports that supply the rentier Iraqi economy, although Iraq has a tourism environment that qualifies it to be attractive to tourism throughout the year, as it has a set of factors that make it at the forefront of countries attracting tourism with its tourism ingredients, despite that, tourism in Iraq suffers from several problems, including the lack of safety requirements in tourism facilities, As the research problem is represented by the high number of accidents in markets, commercial centers, hotels and tourist facilities, table 1 shows the number of fire accidents suffered by markets, commercial centers, hotels and tourist facilities for the period from 2013 to 2017.

Table 1: Fire accidents in markets, commercial centers, hotels and tourist facilities for the period from 2013 to 2017

\begin{tabular}{|l|c|c|c|c|c|c|}
\hline \multirow{2}{*}{ Activity } & \multirow{2}{*}{ The number of accidents } & \multicolumn{3}{c|}{ Material losses } & \multicolumn{2}{c|}{ Human losses } \\
\cline { 3 - 7 } & & Simple & Medium & Serious & Injury & Death \\
\hline Markets and commercial centers & 1728 & 287 & 612 & 879 & 439 & 184 \\
\hline Hotels and tourist facilities & 315 & 115 & 89 & 111 & 74 & 12 \\
\hline Total & 2043 & 402 & 701 & 990 & 423 & 196 \\
\hline
\end{tabular}

Source: federal board of supreme audit report

In view of the high incidence of material and human accidents, the research aims to evaluate the procedures of the federal board of supreme audit in evaluating safety requirements for accidents in markets, commercial centers, hotels, and tourist facilities. however, the research was based on the inductive side, by reviewing a large number of studies on safety and security, and means to achieve development in the tourism sector.

\section{The results of the evaluation of the federal board of supreme audit report}

The positive aspects in evaluating of the federal board of supreme audit report 
The special policies and programs report focused on safety requirements of accidents in markets, commercial centers, hotels, and tourist facilities, as also focused on the negative aspects and safety requirements in commercial markets, restaurants, and amusement parks, and the weak response of the directorate of civil defense regarding accidents, as well as their follow-up to safety measures in commercial centers, restaurants, and amusement parks, however, this report is similar to the performance evaluation report, but it differs from it in that it focuses on a specific policy, such as the policy studied in the report, which is 'providing and implementing safety and disaster reduction requirements', since this policy may include several areas or governorates other than the performance evaluation report that includes several areas specific to a single entity or a specific economic unit.

Among the positives of this prepared report is the temporal selection of the problem and for a period of five years from 2013 to 2017, which gives a clear picture of the problem, and the report was prepared according to the structure of the report of evaluating the policies and programs approved in the federal board of supreme audit, which depends on the International Organization of Supreme Audit Institutions Standards (INTOSAI) in the controlling and evaluation of performance.

\section{The lack in the aspects of the federal board of supreme audit report}

\section{Aspects of the report of the Office of Financial Supervision}

- The report does not contain answers regarding the auditing questions mentioned in the report.

- Some indicators are not clear as to how to reach them.

- There is no logical comparison between what is found in Iraq with any international standards, as it did not take into account the quality standards of the United Nations World Tourism Organization.

- Most of the standards are descriptive, derived from the laws and regulations adopted from the report provider (Auditing Standards).

- The report deals with incidents occurred in hotels in religious areas only.

- The report focused on the problems of accidents in the commercial markets and neglected a large part of the reality of safety and security in other tourist facilities, which are the most important among those tourism facilities, and the most important of which are archaeological facilities.

- The report did not provide notes relating to the safety requirements in hotels.

- The results of the report indicate that they are the results of an evaluation of performance, and lacked the financial aspects and the extent of their impact on the economy in the form of cash sums, as the report did not refer to the losses sustained by the tourism sector due to the losses incurred by this sector, as well as the losses due to the disruption of its activities due to those accidents.

- The report did not explain the losses due to the deliberate neglect of the tourism sector, which is no longer an attractive sector for tourism in the country.

- The non-participation of a specialized health team or examination equipment that contributes to measuring the impact of the materials used in commercial markets on civil defense teams in particular and the environment in general.

- The report did not follow up on the responsibility of the competent electricity departments to follow up on the violations of the electrical network, which may be one of the causes of fire in the commercial markets.

- The report did not mention the necessity of the presence of tourist police that handles the requirements of tourist security in order to detect, protect and develop important tourist sites.

\section{CONCLUSIONS}

The study suggests to submit proposals for designing an auditing program in the light of the requirements of the World Tourism Organization, in light of the report of the World Tourism Organization, and what has been extrapolated from previous literature in the field of achieving safety in tourism facilities, and these requirements include four dimensions that contribute to achieving safety and safety requirements, as well as achieving Tourism development, and these dimensions are: The government dimension: It includes government plans and policies towards developing the reality of tourism, and it did not include checking government policies in developing the tourism sector. The economic dimension: It includes four topics, starting with how to measure tourism and its economic contribution, examining the economic and commercial environment and the investment environment, addressing the issue of the tourism product, and finally reaching the study of security risks in tourism. The operational dimension: which includes the appropriate act and human capital, which consists of two main axes, namely human resources planning, working conditions, qualifications, and training. The need to apply the standards of the World Tourism Organization, including safety and 
security requirements, given that tourism, whether it is a product or service, should not be allowed to affect the lives of tourists.

\section{References}

[1]. Liebowitz, Jay; Megbolugbe, Isaac, "A set of frameworks to aid the project manager in conceptualizing and implementing knowledge management initiatives" [J] International Journal of Project Management 21 (2003) pp. 189-198

[2]. WANG Zhong-tuo,"Knowledge Management in Project Management", Journal of Wuhan Automotive Polytechnic University Vol. 25 No. 32003.6. ISSN:1007-144X.0.2003-03-001 (in Chinese)

[3]. ThePMI Standards Committee. A Guide to the Project Management Body of Knowledge[Z]. Philadelphia:Project Management Institute , 2000.

[4]. Huang, Jimmy C.; Newell, Sue "Knowledge integration processes and dynamics within the context of cross-functional projects" [J] International Journal of Project Management 21 (2003) pp. 167-176

[5]. Fernie, Scott; Green, Stuart D.; Weller, Stephanie J.; Newcombe, Robert; "Knowledge sharing: context, confusion and controversy" [J] International Journal of Project Management 21 (2003) pp. 177-187

[6]. Shu-Sheng Liaw, Gwo-Dong Chen, Hsiu-Mei Huang; "Users' attitudes toward Web-based collaborative learning systems for knowledge management", [J] Computers and Education April 2008 pp 950-961

[7]. Currie, Wendy L. "A knowledge-based risk assessment framework for evaluating web-enabled application outsourcing projects" [J] International Journal of Project Management 21 (2003) pp. 207-217

[8]. Kuan Yew Wong and Elaine Aspinwall, "Development of a knowledge management initiative and system: A case study" [J] Expert Systems with Applications May 2006, pp. 633-641

[9]. Nonaka I;Takeuchi H. The Knowledge Creating Company[M] . New York :Oxford University Press , 1995.

[10]. Jean-paul A.barthes,Cesar A.Tacla; "Agent-supported portals and knowledge management in complex R\&D projects". [J]Computer in industry 48(2002) pp3-16.

[11]. Schindler,Martin; Eppler,Martin J. "Harvesting project knowledge: a review of project learning methods and success factors" [J] International Journal of Project Management 21 (2003) pp. 219-228

[12]. Chua, Alton, "Knowledge management system architecture: a bridge between KM consultants and technologists" [J] International Journal of Information Management 24( 2004),pp. 87-98

[13]. Ho, Cheng-Ter; Chen, Yuh-Min; Chen, Yuh-Jen; Wang, Chin-Bin;" Developing a distributed knowledge model for knowledge management in collaborative development and implementation of an enterprise system" [J]Robotics and Computer-Integrated Manufacturing, October, 2004, pp. 439-456 